\title{
Tradable Immigration Quotas
}

Jesus Fernandez-Huertas Mortaga and Hillel Rapoport

CID Working Paper No. 221

June 2011

(c) Copyright 2011 Jesus Fernandez-Huertas Mortaga, Hillel Rapoport, and the President and Fellows of Harvard College
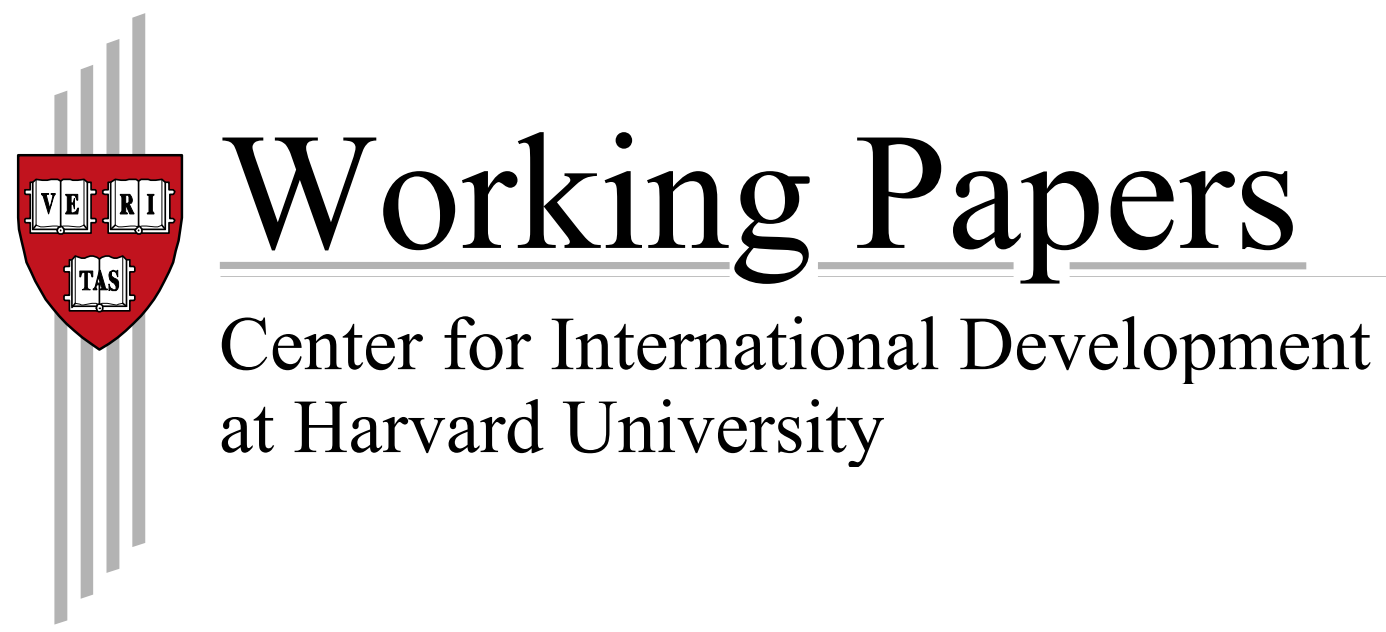


\title{
Tradable Immigration Quotas*
}

\author{
Jesús Fernández-Huertas Moraga ${ }^{a}$ and Hillel Rapoport ${ }^{b}$ \\ ${ }^{a}$ FEDEA and IAE (CSIC) \\ ${ }^{b}$ Center for International Development, Harvard University; \\ Bar-Ilan University; and EQUIPPE, University of Lille
}

June 7, 2011

\begin{abstract}
International migration is maybe the single most effective way to alleviate poverty at a global level. When a given host country allows more immigrants in, this creates costs and benefits for that particular country as well as a positive externality for all those (individuals and governments) who care about world poverty. This implies that the existing international migration regime is inefficient as it fails to internalize such externality. In addition, host countries quite often restrict immigration due to its apparently unbearable social and political costs. However these costs are never measured and made comparable across countries. In this paper we first discuss theoretically how tradable immigration quotas (TIQs) can reveal information on such costs and, once coupled with a matching mechanism taking into account migrants' preferences, generate substantial welfare gains for all the parties involved. We then propose two potential applications: a market for the resettlement of international (e.g., climate change) refugees, and an extension of the US diversity lottery to a larger set of host countries and other immigration targets. Both applications are seen as possible precursors to a full implementation of a TIQs system.
\end{abstract}

JEL Classification: F22, F5, H87, I3, K33, 019.

Key words: immigration, immigration policy, tradable quotas, refugees, climate change, international public goods

*Jesús Fernández-Huertas Moraga: FEDEA, Jorge Juan, 46, 28001 Madrid, Spain. Email: jfernandezhuertas@fedea.es. Hillel Rapoport: Center for International Development, Kennedy School of Government, Harvard University, 79 JFK Street, Cambridge, MA 02138. Email: hillel_rapoport@hks.harvard.edu. We thank Alberto Abadie, Ran Abramitsky, Omer Biran, George Borjas, Roberto Burguet, María Calle, Alessandra Casella, Kfir Eliaz, Avner Greif, Glenn Loury, Igal Milchtaich, Lant Pritchett, Dani Rodrik, David Weil, participants at the $4^{\text {th }}$ INSIDE Workshop (Barcelona), the $3^{\text {rd }}$ AFD-World Bank Migration and Development Conference, the 2010 Meeting of the Spanish Economic Association, the Norface Conference at UCL, and seminar audiences at IAE (CSIC), Lille, Paris School of Economics, Toulouse School of Economics, Harvard Kennedy School, Harvard Center for Population and Development Studies, Science Po, Stanford, Louvain and Brown, for comments and suggestions. We are particularly indebted to David De la Croix and Frédéric Docquier for stimulating exchanges and to Lídia Brun for helpful research assistance. 
I am distressed by the sight of poverty; I am benefited by its alleviation; but I am benefited equally whether I or someone else pays for its alleviation (Milton Friedman, "Capitalism and Freedom", 1962, page 191)

\section{Introduction}

People care about poverty out of altruism (i.e., genuine concern for others' well-being) and self-interest, because they fear for their security, health, and property. To the same extent that domestic poverty alleviation has the dimension of a domestic public good, international poverty alleviation has the dimension of an international public good. Whenever a given country increases its foreign aid to one of the countries where many of the world's poor live, this generates a positive externality for all those in the world, individuals and governments, who care about international poverty reduction (assuming foreign aid is effective at reducing global poverty). Whenever a given country chooses to "let their people come" (Pritchett, 2006), increasing the number of immigration visas granted to nationals of one of the countries where many of the world poor live, this generates a positive externality for all those who care about international poverty reduction (to the extent that international migration is effective at reducing global poverty). In both cases and given the public good nature of poverty alleviation, free riding is likely to prevail and result in global under-provision of foreign aid, debt relief programs, and immigration visas. While the international community has established international organizations and set up institutions to coordinate foreign aid and debt relief efforts, no such institutional setting exists for international migration.

In reality, high-income countries quite often restrict immigration of poor people from poor countries due to its apparently unbearable social and political costs. However these costs are never measured and made comparable across countries. This paper shows theoretically that a system of tradable immigration quotas (TIQs), coupled with a matching mechanism taking the migrants' preferences into account, can elicit information revelation on both the migrants and host countries sides and generate substantial welfare gains for all the parties involved. The matching component is essential because, in contrast to pollution particles - a wellknow application of tradable quotas -, people have preferences over their location. Taking these preferences into account, however, creates opportunities for strategic behavior that may undermine the efficiency of the proposed system, as discussed and addressed in Section 2. Finally, the feasibility of this system is evaluated in Section 3 against the background of two relatively small-scale applications: a market for the resettlement of international refugees (including climate change refugees), and an extension of the US diversity lottery program to more receiving countries and other targeted migrant populations. Both applications allow for considerable experimentation and learning and are seen as possible precursors to a larger implementation of a TIQs system. 


\subsection{Going for the real gains}

Globalization is quite advanced for goods and capital but still very imperfect for low-skill labor mobility. Partly due to this asymmetry in the extents of globalization at different margins, the potential gains from even a small liberalization of international migration are orders of magnitude higher than, say, a full liberalization of trade in goods and services, a comprehensive full debt relief program, or a doubling of official development aid (Pritchett, 2006, 2010). For example, a recent World Bank study (Walmsley, Winters and Ahmed, 2009) develops a bilateral migration model to simulate the welfare gains from an increase in South-North migration representing 3 percent of the labor force in the receiving countries and being served by workers from developing countries in proportion to their traditional supplies to each developed economy; according to their computations, this modest liberalization of international migration would increase global GDP by US $\$ 288$ billion, a surplus shared more or less equally between the migrants, home country residents and host country residents thanks to the induced remittances. This is to be compared to a previous study by the same authors where a full liberalization of trade would increase world output by just 65 billion. In the words of Rodrik (2007, p. 240), allowing for more international mobility of workers today is really "going for the real gains".

However, the above figures are silent with respect to the poverty-reduction effect of international migration because they do not inform us on its distributional impact across and within developing countries. Recent micro literature, however, reveals that this impact is substantial both directly (i.e., through the extraction of migrants out of poverty) and indirectly, through the developmental impact of migration on source countries.

The main difficulty in measuring the income gains accruing to migrants as a result of migration is to produce sensible counterfactuals of domestic earnings for migrants, accounting not just for their observable characteristics but also for unobservables such as motivation at work, attitudes toward risk, cognitive ability, etc. McKenzie, Gibson and Stillman (2010) use the New Zealand migration lottery program to "clean" income gains for migrants from such self-selection effects. Comparing lottery-winning migrants to lottery-losing non-migrants they find migration increases migrants' earnings by a factor of four (from NZ $\$ 104$ to 424 for weekly wages). This is consistent with the non-experimental results of Clemens, Montenegro and Pritchett (2008) who compare workers in developing countries to workers from the same countries working in the United States. After controlling for workers' characteristics, migration is found to raise real wages by 200 percent, 250 percent and 680 percent respectively for Guatemalans, Filipinos and Haitians. These income gains would seem to exceed the potential gains of any in situ development policy by orders of magnitude. For example, they calculate that the total present value of access to a lifetime of micro-credit is equivalent to the wage difference of just four weeks work of the same worker in the USA versus in Bangladesh, or that the present value of a lifetime wage increment of one additional year of schooling (obtained at no cost) is equivalent to 11 weeks work of the same worker in the USA versus in Bolivia.

Are we certain, however, that making migrant workers richer effectively contributes to reduce poverty at the world level? The effects of migration on poverty reduction through 
the direct extraction of migrants out of poverty are maybe best illustrated using figures put together by Clemens and Pritchett (2008) using three poverty standards at US $\$ 1,2$ and 10 per day (in PPP). Respectively 50, 75 and 93 percent of all Haitian "naturals" (people born in Haiti) live below the $\$ 1,2$ and 10 poverty lines. Out of the 25 percent of all Haitians between the first two lines, 26 percent are US immigrants. Out of the 18 percent between the last two lines, 82 percent are US immigrants. By the latter measure, among the 56 percent of all Mexicans between the last two lines, 43 percent are US immigrants. While it would be an abuse of language to interpret these figures as indicative of the share of people escaping poverty thanks to migration, they are clearly suggestive of large direct effects of migration on poverty reduction. In addition, these figures may be seen as conservative. For example, in the case of Mexico, they neglect the induced effects of migration on poverty through increased wages for low-skill workers (Mishra, 2007), consumption of remittance income, and the fact that there is evidence of negative selection into migration both on observables and unobservables, meaning that migrants would on average earn less in Mexico if they had not migrated than those who did not migrate (Fernández-Huertas Moraga, 2011). More generally, we know that while migrants initially come from the middle of the income and wealth distribution, network and other dynamic effects act to reduce migration costs, making migration affordable for people down on the income ladder. This generates poverty and inequality reducing effects both directly, through migrants' self-selection patterns, and indirectly, through general equilibrium effects and distributional effects of remittances gradually reaching poorer households (McKenzie and Rapoport, 2007, 2010, Shen et al., 2010).

\subsection{Visas, Not Aid! Alternative strategies of international poverty reduction}

The international community (supported by public opinions in Western countries) commonly supports poor countries at political, economic, and environmental risk, or sub-sets of their populations displaced by civil war, ethnic conflict and natural disasters, through emergency aid. Similarly, the growth and development prospects of poor countries are supported through development aid, debt relief programs, and in situ development projects. Since the late 1960s, however, the slogan "trade, not aid" has symbolized developing countries' aspirations to trade aid for better access to rich countries' markets. A "visas, not aid" slogan may well gain momentum and convey the idea that aid could be traded, at least partly, for better access to rich countries labor markets.

The idea that visas can be used as part of an aid relief strategy first materialized when the US Temporary Protected Status (TPS) mechanism, enacted in 1990, was applied to thousands of Hondurans and Nicaraguans in the aftermath of Hurricane Mitch in 1998 (UNHCR, 2009). TPS was also granted to illegal Salvadorian immigrants following the earthquakes that devastated El Salvador in 2001. Interestingly, the decision was made by then President George W. Bush at the explicit request of his Salvadorian counterpart, Fransisco Flores, during a White House meeting. The status allowed 150,000 undocumented Salvadorians to 
legally remain in the United States for eighteen months. ${ }^{1}$ More recently, TPS was also granted to tens of thousands of illegal Haitians immigrants following the earthquake in Haiti in 2010.

Can visas be also used to promote long-run growth, either as complements or substitutes to development aid? A look at the global comparative figures on aid and remittances suggests a positive answer. Officially recorded remittances to developing countries have more than tripled over the last decade, rising from US $\$ 57$ billion in 1995 to US $\$ 85$ billion in 2000 and US $\$ 328$ billion in $2008 .^{2}$ While in 1995 remittances and official development aid were of comparable size, by 2008 remittances had tripled the size of foreign aid. Moreover, remittances have been celebrated as a more effective source of foreign exchange for development and poverty alleviation thanks to its private, highly decentralized nature, and to migrants' comparative advantage in targeting recipients. ${ }^{3}$ As noted above, migration and the induced remittances have been a powerful force in the fight against global poverty while the contribution of foreign aid to poverty reduction is at best controversial (Easterly, 2001).

Our main point, however, is elsewhere. To the same extent that the international community has called repeatedly for the rich nations to contribute to development aid and assistance on a fair basis, often setting quantitative objectives such as " 0.7 percent of GDP", one may ask whether some countries contribute more than others to development and global poverty reduction through their welcoming more immigrants from poor countries. As can be seen from Table 1, on average the OECD high-income countries contributed 0.2 percent of their GDP to foreign aid in 2000. The only countries which approach or reach the one percent mark are Denmark, Luxembourg, Netherlands, Norway and Sweden. The United States, on the other hand, contributed just 0.1 percent of its GDP to ODA in 2000, one of the lowest figures among countries with comparable GDP per capita. However, the US, with a GDP representing two fifths of the total GDP of OECD high-income countries in 2000 was host to 45 percent of the non-tertiary educated immigrants from Low-Income Countries in 2000 and received more than 51 percent of the flow of immigrants from these countries between 1990 and 2000. Countries such as Australia, Canada, Iceland or the UK welcomed more than twice as many non-tertiary educated immigrants from poor countries as what an allocation according to GDP shares would predict, and conversely for countries such as Australia, Ireland, Japan or Luxemburg (less than 50 percent). The most extreme case is that of Japan, with respectively 19, 25 and 3 percent of the group's output, ODA and stock of immigrants from low-income countries.

\footnotetext{
${ }^{1}$ President Bush was quoted saying: "This will allow them to continue to work here and to remit some of their wages back home to support El Salvador's recovery efforts." The New York Times, March 3, 2001.

${ }^{2}$ The recent economic crisis resulted in a decline in remittances of about 5 percent in 2009, though 2010 saw a rebound by about the same amount.

${ }^{3}$ See World Bank (2006). See also Rapoport and Docquier (2006) for a survey of the literature on migrants' remittances.
} 
Table 1: OECD high-income countries' respective contribution to Foreign Aid and to low-skill immigration from Low Income Countries.

\begin{tabular}{|c|c|c|c|c|c|c|c|}
\hline Countries & $\begin{array}{c}\text { GDP } \\
\text { per } \\
\text { capita } \\
\text { in } \\
2000 \\
(\mathrm{US}=100)\end{array}$ & $\begin{array}{l}\text { GDP } \\
\text { in } \\
2000 \\
(\%)\end{array}$ & $\begin{array}{l}\text { ODA } \\
\text { in } \\
2000 \\
(\%)\end{array}$ & $\begin{array}{l}\text { Low-skill } \\
\text { Migrant } \\
\text { Stock } \\
\text { from LICs } \\
\text { in } 2000 \\
\quad(\%)\end{array}$ & $\begin{array}{c}\text { Low-skill } \\
\text { Net flow } \\
\text { from } \\
\text { LICs } \\
1990-2000 \\
(\%)\end{array}$ & $\begin{array}{c}\text { ODA } \\
\text { share/ } \\
\text { GDP } \\
\text { share }\end{array}$ & $\begin{array}{c}\text { Migration } \\
\text { stock } \\
\text { share/ } \\
\text { GDP } \\
\text { share }\end{array}$ \\
\hline Australia & 61 & 1.7 & 1.9 & 4.3 & 5.6 & 1.1 & 2.5 \\
\hline Austria & 69 & 0.8 & 0.8 & 0.1 & 0.3 & 1.0 & 0.2 \\
\hline Belgium & 65 & 1.0 & 1.5 & 1.6 & 0.2 & 1.6 & 1.7 \\
\hline Canada & 68 & 3.0 & 3.2 & 6.4 & 5.7 & 1.1 & 2.1 \\
\hline Denmark & 87 & 0.7 & 3.1 & 0.7 & 1.2 & 4.7 & 1.0 \\
\hline Finland & 68 & 0.5 & 0.7 & 0.2 & 0.5 & 1.4 & 0.4 \\
\hline France & 63 & 5.5 & 7.5 & 10.3 & 5.9 & 1.4 & 1.9 \\
\hline Germany & 67 & 7.9 & 9.4 & 3.9 & 3.3 & 1.2 & 0.5 \\
\hline Greece & 33 & 0.5 & 0.4 & 0.3 & 0.0 & 0.8 & 0.5 \\
\hline Iceland & 89 & 0.0 & 0.0 & 0.1 & 0.1 & 0.4 & 2.1 \\
\hline Ireland & 73 & 0.4 & 0.4 & 0.1 & 0.1 & 1.1 & 0.1 \\
\hline Italy & 56 & 4.6 & 2.6 & 2.6 & 2.8 & 0.6 & 0.6 \\
\hline Japan & 106 & 19.4 & 25.1 & 3.1 & 2.6 & 1.3 & 0.2 \\
\hline Luxembourg & 134 & 0.1 & 0.2 & 0.0 & 0.0 & 2.7 & 0.3 \\
\hline Netherlands & 70 & 1.6 & 5.9 & 1.9 & 1.7 & 3.7 & 1.2 \\
\hline New Zealand & 38 & 0.2 & 0.2 & 0.4 & 0.5 & 1.0 & 1.8 \\
\hline Norway & 108 & 0.7 & 2.3 & 0.7 & 0.9 & 3.4 & 1.0 \\
\hline Portugal & 32 & 0.5 & 0.5 & 0.6 & 1.0 & 1.1 & 1.2 \\
\hline Spain & 42 & 2.4 & 2.3 & 1.2 & 1.7 & 0.9 & 0.5 \\
\hline Sweden & 80 & 1.0 & 3.3 & 1.2 & 1.8 & 3.3 & 1.2 \\
\hline Switzerland & 101 & 1.0 & 1.6 & 0.9 & 0.7 & 1.6 & 0.8 \\
\hline UK & 73 & 6.1 & 8.5 & 14.9 & 12.2 & 1.4 & 2.4 \\
\hline USA & 100 & 40.5 & 18.5 & 44.7 & 51.2 & 0.5 & 1.1 \\
\hline Sum & & 100.0 & 100.0 & 100.0 & 100.0 & & \\
\hline $\begin{array}{l}\text { Total } \\
\text { Source }\end{array}$ & WDI & $\begin{array}{c}\$ 24 \mathrm{tr} . \\
\text { WDI }\end{array}$ & $\begin{array}{l}\$ 54 \text { bi. } \\
\text { OECD }\end{array}$ & $\begin{array}{c}2.5 \mathrm{mi} . \\
\mathrm{DM}\end{array}$ & $\begin{array}{l}1 \mathrm{mi} . \\
\mathrm{DM}\end{array}$ & & \\
\hline
\end{tabular}

Notes: The Docquier and Marfouk (2006) data refer to immigrants aged 25 and older.

Low income countries are defined according to the World Bank classification. 


\subsection{Related literature}

A case can thus be made that i) there is a global under-provision of immigration visas to the rich countries and ii) the current contributions to global poverty alleviation through the provision of immigration visas are not shared "fairly" (i.e., some countries are home to a substantial number of international migrants originating from poor countries while others are virtually closed to such immigration). Restrictive immigration policies are often justified by non-economic costs such as threats to social cohesion and national identity, which translate into negative attitudes toward immigration and constitute a political barrier to freer labor mobility (Mayda, 2008; Facchini and Mayda, 2008; Hanson, Scheve and Slaughter, 2007; O'Rourke and Sinnott, 2006). ${ }^{4}$ Differences in the perceived costs from immigration across countries may come from different demographic structures (e.g., dependency ratios), histories of previous immigration, or inherited preferences for ethnic, religious and cultural diversity. We do not dispute these preferences and take them as given. While a TIQs system would likely result in less open (more xenophobic) countries compensating immigration-friendly ones for their higher direct contribution to international poverty reduction through immigration, the rationale for such a system is purely an efficiency one, not a preference building (or rewarding) one, the essence of the argument being about information revelation on the true costs and benefits of letting more migrants in. ${ }^{5}$ We also note that differences in preferences over immigration policy, as well as other causes for divergence in the perceived costs of immigration across countries are a source of comparative advantage for some countries in hosting immigrants. A system of tradable immigration quotas creates an opportunity to exploit such comparative advantage.

To the best of our knowledge, the idea of tradable immigration quotas was first discussed in the case of refugees by scholars in the field of international law (Schuck, 1997, Hathaway and Neve, 1997). De la Croix and Gosseries (2007) mention the possibility of tradable migration quotas for unskilled migrants. However they do not model the idea formally, consider temporary migration only, and couple this proposal with a source country market for emigration rights among skilled migrants, which they see as an alternative to a Bhagwati tax. Similarly, Pritchett (2006) discusses a number of variants of guest-worker programs, where migration is temporary and workers have no political rights (this is not "immigration" as there is no prospect for a full, long-term integration).

The closest related paper is certainly De la Croix and Docquier (2010), who also stress that a higher level of low-skill immigration than what is currently observed would contribute to reduce world poverty, and propose a tax-subsidy scheme to encourage rich countries to accept more low-skill immigrants than they would unilaterally admit in a way that ensures voluntary participation in the scheme. The tax would consist of contributions to a global fund that would then be refunded through a subsidy as countries accept more immigrants. Their focus is on participation constraints to ensure the political feasibility of their proposal.

\footnotetext{
${ }^{4}$ On the economic costs, see Hanson (2009).

${ }^{5}$ From a dynamic perspective however, one can also envision that once the consequences of xenophobic preferences are internalized, people may have incentives to become less xenophobic.
} 
However, political feasibility crucially hinges on a correct determination of the appropriate tax and subsidy levels, for which the informational requirements of their model might seem excessive. For example, in the quantitative assessment of the model, they ask participating countries for contributions to the global migration fund in a range going from 0.1 to 0.2 percent of GDP that countries would recover if the tax and subsidy levels are correctly designed but could generate big losses on particular countries otherwise.

The mechanism proposed in this paper is less demanding in terms of informational requirements since the revelation of the true net costs of migration that countries face is precisely one of its main objectives. It may equally apply to temporary, humanitarian or permanent economic migration. Differently from De la Croix and Docquier (2010), we initially leave participation constraints outside of the model. However, our model can satisfy participation constraints through the manipulation of initial quotas (see Appendix A); this requires knowledge about the net cost of migration for all the countries involved, an information which is unknown ex-ante (but can be revealed over time through the market). Another efficiency advantage of the mechanism we propose it that it takes into account the fact that migrants have preferences over locations, something that has been ignored by previous literature. While we do not strive for a first best solution, the proposed mechanism ensures a cost-minimizing way of attaining a higher, Pareto-improving level of low-skill immigration from developing countries than what is currently observed. Political feasibility, on the other hand, is a likely by-product of the incrementalist approach we advocate; indeed, the initial small-scale applications we envision should allow for considerable learning and for gradual extensions of the mechanism over time.

\section{The Model}

\subsection{TIQs with homogenous agents}

We start by assuming that each individual country $i$ faces a decision about the number of immigrants $\left(m_{i}\right)$ to let in and that the net cost of receiving these immigrants is described by a cost function $c_{i}\left(m_{i}\right)$. The cost function is a reduced form taking into account diverse components such as the direct cost of receiving immigrants, administrative costs of processing their visa applications, social costs inherent to possible conflicts with the local population, political costs associated with xenophobic sentiments, as well as all the economic and social cost and benefits that migrants may bring about (e.g., the immigration surplus, immigrants' net fiscal contribution, and the value for country $i$ of its contribution to reducing global poverty by receiving $m_{i}$ immigrants). It is assumed that $c_{i}\left(m_{i}\right)$ is a convex differentiable function in the number of migrants with an interior positive minimum. Nothing is said about the sign of the cost function to allow for the possibility that immigrants are considered either a net burden (positive cost) or are positively valued (negative cost) by the destination country.

In this section we treat migrants as homogenous in the sense that we assume all potential 
immigrants to be indifferent between going to any of the $N$ possible destination countries, ${ }^{6}$ an assumption that will be relaxed in Section 2.2. Another important assumption is that destination countries can effectively choose the number of immigrants they want. In this sense, a destination country $i$ would be solving the following maximization problem:

$$
\max _{m_{i}} g_{i}\left(M_{-i}\right)-c_{i}\left(m_{i}\right)
$$

where $g_{i}(\cdot)$ captures the externality for country $i$ from immigration to other rich countries and $M_{-i}=\sum_{j \neq i} m_{j} \cdot{ }^{7}$ The optimal solution is:

$$
c_{i}^{\prime}\left(m_{i}^{N C}\right)=0
$$

where $N C$ stands for the non-cooperative solution. As explained in the previous section, immigration to one country generates a positive externality for the other countries. Hence, the non-cooperative equilibrium does not satisfy a general optimal level $M^{G O}$. To see why this is the case, consider the global optimal problem:

$$
\max _{\left\{m_{i}\right\}_{i=1}^{N}} \sum_{i=1}^{N}\left[g_{i}\left(M_{-i}\right)-c_{i}\left(m_{i}\right)\right]
$$

The first order conditions are:

$$
-c_{i}^{\prime}\left(m_{i}^{G O}\right)+\sum_{j \neq i} g_{j}^{\prime}\left(M_{-j}^{G O}\right)=0 \quad \forall i=1 \ldots N
$$

Since $g_{i}^{\prime}(\cdot)>0$, we have $c_{i}^{\prime}\left(m_{i}^{G O}\right)=\sum_{j \neq i} g_{j}^{\prime}\left(M_{-j}^{G O}\right)>0=c_{i}^{\prime}\left(m_{i}^{N C}\right)$ and thus $m_{i}^{G O}>$ $m_{i}^{N C}$. The Nash solution $\left(m_{i}^{N C}\right)$ clearly implies a lower level of migration than it is desirable at the world level: ${ }^{8}$

$$
M^{N C} \equiv \sum_{i=1}^{N} m_{i}^{N C}<\sum_{i=1}^{N} m_{i}^{G O} \equiv M^{G O}
$$

Assume now that $N$ countries sign a multilateral agreement, or a central authority steps in to coordinate these countries towards a higher level of total international migration $M$ (decided outside of the model) such that:

$$
M^{N C}<M<M^{G O}
$$

\footnotetext{
${ }^{6}$ Note that immigrants are also considered to be "homogeneous" from the point of view of the receiving countries. The net cost of an immigrant can be interpreted as the expected net cost of a typical or average migrant. We discuss this point in more detail in Section 2.2.

${ }^{7}$ Given that the externality is linked to the induced reduction of poverty at the world level, we assume that $g_{i}^{\prime}(\cdot)>0$.

${ }^{8}$ For a more explicit modeling of the externality in the case of refugee protection, see Barbou des Places and Deffains (2004), Hatton (2004), Hatton and Williamson (2004) or Bubb, Kremer and Levine (2009). In the case of immigration, see De la Croix and Docquier (2010).
} 
That is, the agreement would go part of the way towards achieving an optimal global level of international migration.

The problem that must be solved by this central authority can be stated as:

$$
\begin{aligned}
\max _{\left\{m_{i}\right\}_{i=1}^{N}} & \sum_{i=1}^{N}\left[g_{i}\left(M_{-i}\right)-c_{i}\left(m_{i}\right)\right] \\
\text { s.t. } & \sum_{i=1}^{N} m_{i} \leq M
\end{aligned}
$$

The first order conditions are:

$$
-c_{i}^{\prime}\left(m_{i}^{c m}\right)+\sum_{j \neq i} g_{j}^{\prime}\left(M_{-j}^{c m}\right)+\pi=0 \quad \forall i=1 \ldots N
$$

where $\pi$ is the multiplier associated to the constraint. It must also be true that:

$$
\pi\left(M-\sum_{i=1}^{N} m_{i}^{c m}\right)=0
$$

Since $g_{i}^{\prime}(\cdot)>0$ and the multiplier associated to the constraint $\pi \geq 0$, we know as before that $c_{i}^{\prime}\left(m_{i}^{c m}\right)=\sum_{j \neq i} g_{j}^{\prime}\left(M_{-j}^{c m}\right)+\pi>0=c_{i}^{\prime}\left(m_{i}^{N C}\right)$ so that $m_{i}^{c m}>m_{i}^{N C}$ and $\sum_{i=1}^{N} m_{i}^{c m}>M^{N C}$.

Since $\sum_{i=1}^{N} m_{i}^{N C}=M^{N C}<M$, we can then be sure that $\pi>0$, so that:

$$
M=\sum_{i=1}^{N} m_{i}^{c m}
$$

The optimal solution for this constrained maximization problem equates the marginal cost of accepting one additional immigrant $\left(c_{i}^{\prime}\left(m_{i}^{c m}\right)\right)$ for a given number of immigrants $M$ to the shadow price of increasing the size of the program $(\pi)$ plus the sum of the welfare gains obtained elsewhere when country $i$ decides to accept one additional immigrant $\left(\sum_{j \neq i} g_{j}^{\prime}\left(M_{-j}^{c m}\right)\right)$. If we assume that these welfare gains are common to all participating countries (for example, take $g_{i}\left(M_{-i}\right)=\beta M_{-i}$ ), the optimal solution for this constrained maximization problem will completely equalize marginal costs across destination countries. In the linear example, the solution would be: $c_{i}^{\prime}\left(m_{i}^{c m}\right)=(N-1) \beta+\pi \equiv \lambda$.

Let us now assume that the above solution is implemented by creating a market for immigration quotas that would open for a limited time, after which immigrants receive visas for their final destinations. Under this system, each country is assigned an initial quota of immigrants $m_{i 0}$ that can then be traded in a market in which the price for accepting one additional immigrant will be represented by $p .{ }^{9}$ The initial distribution of quotas must be

\footnotetext{
${ }^{9}$ The notion of paying a price to avoid migration might not appear very attractive politically. This can easily be circumvented by wording the proposal so that countries have two means for contributing to poverty
} 
agreed upon by the countries participating in the multilateral agreement or established by a central authority and be such that:

$$
M=\sum_{i=1}^{N} m_{i 0}
$$

It is assumed that the cost functions are expressed in monetary units and that the market is competitive so that all countries behave as price-takers. ${ }^{10}$ The problem that each country must solve in this case is:

$$
\min _{m_{i}} c_{i}\left(m_{i}\right)-p\left(m_{i}-m_{i 0}\right)
$$

If the market is competitive, the first order condition will be:

$$
c_{i}^{\prime}\left(m_{i}^{M}\right)=p
$$

The marginal costs of accepting one additional immigrant will then be equalized through the market. In addition, the market must clear:

$$
M=\sum_{i=1}^{N} m_{i 0}=\sum_{i=1}^{N} m_{i}^{M}
$$

The market solution will be efficient $\left(m_{i}^{M}=m_{i}^{c m}\right)$ as long as it can be proved that $p=\lambda$. To see that this is the case, suppose $p \neq \lambda$. There are two possibilities then:

- $p<\lambda$. From the first order conditions in both problems, this implies: $c_{i}^{\prime}\left(m_{i}^{M}\right)<$ $c_{i}^{\prime}\left(m_{i}^{c m}\right)$ so that $m_{i}^{M}<m_{i}^{c m}$ for all $i$ because of the convexity of $c_{i}\left(m_{i}\right)$. But then $M=\sum_{i=1}^{N} m_{i}^{M}<\sum_{i=1}^{N} m_{i}^{c m}$, a contradiction.

- $p>\lambda$. Following the same reasoning, this implies $m_{i}^{M}>m_{i}^{c m}$ for all $i$ so that $M=\sum_{i=1}^{N} m_{i}^{M}>\sum_{i=1}^{N} m_{i}^{c m}=M$, contradicting the solution to the constrained maximization problem.

It is clear, therefore, that a TIQs system is able to replicate the constrained maximization solution and that the initial distribution of quotas only has redistributive consequences as long as the market is competitive.

A natural question that arises is why the market should be used to solve the externality problem instead of any other mechanism such as taxation. The answer follows the reasoning of Baumol and Oates (1995). The market for tradable quotas and an appropriate Pigouvian tax/subsidy are equivalent in an environment of perfect certainty. However, if we assume

reduction through immigration: bidding visas, or bidding money to fund the settlement of immigrants in third countries.

${ }^{10}$ We discuss the possibility of manipulation of prices by big players in our applications. We follow Casella (1999) in arguing for a market design that alleviates these concerns. 
that the cost functions of individual countries are only known to the countries themselves, the market for tradable quotas is superior to a Pigouvian tax/subsidy since the tax would only ensure a certain level of marginal cost whereas the market makes sure that the final objective (i.e., achieving the agreed upon number of immigrants $M$ ) is attained. ${ }^{11}$ From a Coasian perspective (Coase, 1960), we must also assume that transaction costs (e.g., negotiation costs, the costs of setting a bureaucratic apparatus in charge of implementing the mechanism) are sufficiently low, which is quite realistic given the huge potential welfare gains detailed in section 1 .

\subsection{Taking Migrants' Preferences into Account}

So far we have assumed that an international agency (or a multilateral agreement) determines that $M$ immigrants must be distributed among $N$ countries who agreed to host them in proportion of some pre-determined tradable quotas. At this point, we have a sequence $\left\{m_{i}^{M}\right\}_{i=1}^{N}$ of immigrant assignments for each of the potential destination countries. The problem is now to assign indivisible items (rights for a migrant to enter a given destination country, or "visas") to agents (migrants) taking into account the preferences of the latter. In this sense, the problem is exactly analogous to assigning houses to tenants (Abdulkadiroglu and Sonmez, 1999).

The solution proposed by Abdulkadiroglu and Sonmez (1999) is the use of the top trading cycles mechanism, which in our case where no immigrant has previous rights to enter a particular country, is equivalent to a random serial dictatorship. ${ }^{12}$ The application of the top trading cycles mechanism to the problem at hand would work as follows:

1. Each immigrant ranks all potential destination countries, specifying those to which she would not want to go at all.

2. An ordering of immigrants is randomly chosen from a given distribution of orderings.

3. For any given ranking of countries done by the immigrants and ordering of immigrants, assign the first immigrant her first choice, the second immigrant her first choice and so on until an immigrant chooses first a country whose quota is filled. In that case, assign that immigrant her second choice or, if that one is also filled, her third choice and so on. If all the quotas are filled for the countries for which the immigrant would be willing to go, that particular immigrant is taken out of the mechanism and substituted for another one initially out of the total number $M$.

The described mechanism is individually rational as it ensures every eventual immigrant a visa that is at least as good as the possibility of staying in her original country (participation

\footnotetext{
${ }^{11}$ According to Weitzman's (1974) terminology, the marginal benefit of the externality is perfectly inelastic so that the quantitative restriction (the market) is preferred over the price restriction (Pigouvian tax).

${ }^{12}$ See however Appendix B for an application to refugees' resettlement where migrants have pe-existing rights.
} 
constraint). It is also incentive compatible (no immigrant has an incentive to misrepresent her preferences whatever the strategies others use) and Pareto efficient in the sense that there is no possibility for immigrants to benefit from a mutual exchange of assigned visas. ${ }^{13}$

If such a matching mechanism is introduced, the problem that a central authority would need to solve in order to minimize the total costs of distributing $M$ migrants over $N$ destination countries is completely equivalent to the simple maximization model of the previous section. The solution would just equalize the marginal costs of accepting an additional immigrant across countries.

A potential difficulty arises if one of the $N$ participating destination countries is such an undesirable destination that none of the potential immigrants willing to apply for a visa would consider going there. In such a case, equation (9) would no longer be verified. Notwithstanding this difficulty (that will be addressed at the end of this section), the planner's problem once the above-described matching mechanism is introduced becomes:

$$
\begin{aligned}
& \min _{\left\{m_{i}\right\}_{i=1}^{N}} \sum_{i=1}^{N} c_{i}\left(m_{i}^{*}\right) \\
& \text { s.t. } \quad \sum_{i=1}^{N} m_{i} \geq M \\
& m_{i}^{*}=F_{i}\left(m_{1}, m_{2}, \ldots, m_{N}\right) \quad \forall i=1 \ldots N
\end{aligned}
$$

The last set of constraints embeds the matching mechanism. The sequence $\left\{F_{i}\right\}_{i=1}^{N}$ of functions $F_{i}:[0, M]^{N} \rightarrow[0, M]$ transforms an allocation of visas $\left\{m_{i}\right\}_{i=1}^{N}$ decided by the central planner as if countries were homogenous from the migrants' perspective into another allocation $\left\{m_{i}^{*}\right\}_{i=1}^{N}$ that does take into account migrants' preferences through the matching mechanism. Since it will always be the case that $m_{i}^{*} \leq m_{i}$, as discussed above, this implies that $\sum_{i=1}^{N} m_{i}^{*} \leq M$.

The functions in the sequence $\left\{F_{i}\right\}_{i=1}^{N}$ can be approximated by differentiable functions, for example, by interpolating a polynomial that will take exactly the same values where the matching function is defined. In such a case, the solution to the total minimum cost problem above can be obtained from the following first order conditions:

$$
\sum_{j=1}^{N} \frac{\partial F_{j}}{\partial m_{i}} c_{j}^{\prime}\left(m_{j}^{*}\right)-\lambda=0 \quad \forall i=1 \ldots N
$$

\footnotetext{
${ }^{13}$ This is only correct ex ante. Indeed, once final destinations (assignments) are known, it could well be that two migrants would like to trade places, for example relatives who prefer to be together in a less preferred destination than alone in a more preferred one. In practice, more complex matching mechanisms, such as those described by Roth (2002), could be adopted to prevent families from being divided into different destination countries.
} 
where $\lambda$ is the multiplier associated with the first constraint. The solution to this problem is less intuitive and it does no longer guarantee the equalization of marginal costs across countries unless $m_{i}^{*}=m_{i}^{T M C}$, which can follow from:

$$
\begin{aligned}
& \frac{\partial F_{j}}{\partial m_{i}}=0 \quad \forall i \neq j \\
& \frac{\partial F_{i}}{\partial m_{i}}=1
\end{aligned}
$$

We now ask whether the introduction of a matching mechanism taking migrants' preferences into account affects the ability of a TIQs system to replicate the solution to the total minimum cost problem. In order to answer this question, we look at the problem a representative country $i$ would face:

$$
\begin{aligned}
& \quad \min _{m_{i}} c_{i}\left(m_{i}^{*}\right)-p\left(m_{i}^{*}-m_{i 0}\right) \\
& \text { s.t. } \quad m_{i}^{*}=F_{i}\left(m_{1}, m_{2}, \ldots, m_{N}\right)
\end{aligned}
$$

The first order condition associated with this problem is:

$$
\frac{\partial F_{i}}{\partial m_{i}}\left(c_{i}^{\prime}\left(m_{i}^{*}\right)-p\right)=0
$$

It is clear that at least one of the competitive solutions $\left(c_{i}^{\prime}\left(m_{i}^{*}\right)=p\right)$ would replicate the total minimum cost solution when there are no countries to which no migrants would be willing to go. However, what happens if there are countries to which no migrants want to go? The matching mechanism establishes an implicit penalty for those countries that are not attractive to migrants. The key is that countries pay depending on the final outcome of the matching mechanism $m_{i}^{*}$ rather than on the buying and selling decisions adopted in the market $m_{i}$. In other words, their objective function is $c_{i}\left(m_{i}^{*}\right)-p\left(m_{i}^{*}-m_{i 0}\right)$ rather than $c_{i}\left(m_{i}^{*}\right)-p\left(m_{i}-m_{i 0}\right)$. This generates a penalty for countries that become undesirable destinations. $^{14}$

To see this more clearly, specify the functions $F_{i}\left(m_{1}, m_{2}, \ldots, m_{N}\right)$ as:

$$
\begin{array}{rlr}
m_{j}^{*} & =F_{j}\left(m_{1}, m_{2}, \ldots, m_{N}\right)=m_{j} \quad \forall j \neq i \\
m_{i}^{*} & =F_{i}\left(m_{1}, m_{2}, \ldots, m_{N}\right)=m_{i} & \text { if } m_{i} \leq \bar{m}_{i} \\
& =\bar{m}_{i} \quad \text { otherwise } &
\end{array}
$$

The interpretation is that only $\bar{m}_{i}$ individuals in the world are willing to go to country $i$ even as a last resort.

\footnotetext{
${ }^{14} \mathrm{As}$ a practical matter, this penalty could be collected by the institution or as part of the multilateral aggreement setting up the market.
} 
First, suppose country $i$ cannot affect $\bar{m}_{i}$, the solution would then be characterized by the following first order conditions:

$$
\begin{array}{rlr}
c_{i}^{\prime}\left(m_{i}^{M}\right) & =p \quad \text { if } m_{i}^{M} \leq \bar{m}_{i} \\
m_{i}^{M} & =\bar{m}_{i} \quad \text { otherwise }
\end{array}
$$

Of course, the second solution is the interesting one. It must be noted that, with $m_{i}^{M}=$ $\bar{m}_{i}$, we will have $c_{i}^{\prime}\left(\bar{m}_{i}\right)<p$.

If country $i$ were able to manipulate $\bar{m}_{i}$, it would try to increase it to the point where the marginal cost equates the price. It would have no incentive to decrease its attractiveness as a destination for migrants since it would then have to pay for closing its door to those migrants. If anything, a country that is not attractive to migrants would have incentives to become more attractive so as to be able to equate its marginal cost to the market price.

The reason is that countries are compensated for the immigrants they actually receive rather than for those they demand to receive in the market. To make things simple, suppose that a country receives an initial quota $m_{i 0}$ such that $c_{i}^{\prime}\left(m_{i 0}\right)=p$. For that country, it makes no sense to buy or sell in the market. But now suppose that $m_{i 0}>\bar{m}_{i}$. If countries were compensated according to market outcomes, country $i$ 's cost would be $c_{i}\left(\bar{m}_{i}\right)-p\left(m_{i 0}-m_{i 0}\right)=c_{i}\left(\bar{m}_{i}\right)$. Because of the penalty, country $i$ 's cost is $c_{i}\left(\bar{m}_{i}\right)-p\left(\bar{m}_{i}-m_{i 0}\right)>c_{i}\left(\bar{m}_{i}\right)$. The quantity $p\left(m_{i 0}-\bar{m}_{i}\right)$ would be the penalty for not complying with the number of migrants that the country was supposed to take. It is easy to see that this result extends to any case in which the result from the market is greater than the number of migrants who would actually be willing to go to country $i: m_{i}>\bar{m}_{i}$. It is also clear that the penalty remains implicit as long as countries have perfect knowledge about $\bar{m}_{i}$ (see the solution to the problem above). As will be seen in the applications, this is not an extreme assumption since we can consider that the preferences of refugees or migrants are collected before the market opens. As a way to prevent price manipulations we can even consider restricting market participants to bid up to $\bar{m}_{i}$.

Finally, countries may also have preferences over the types of migrants they receive. Indeed, our current formulation of the marginal cost function $c_{i}^{\prime}\left(m_{i}\right)$ can be interpreted as the marginal cost over ex-ante identical immigrants. In principle, we could allow countries to choose immigrants in the same way in which we allowed immigrants to choose destination countries. In that case, the problem would be equivalent to a college admissions problem (Gale and Shapley, 1962; Roth, 1985). However, there are several reasons why we treat the issue of the immigrants' visas allocation as analogous to allocating tenants to houses (Abdulkadiroglu and Sonmez, 1999) rather than students to colleges (i.e., we neglect the preferences of the receiving party over who is coming). A first reason is purely technical and is related to the impossibility of having a stable Pareto-efficient matching mechanism in which countries (colleges) reveal their preferences truthfully over the type of migrants they want. As demonstrated by Roth (1985) in the context of college admissions, "there exists no stable mechanism that makes it a dominant strategy for each school to state its prefer- 
ences over the students truthfully." 15 A second, more substantive reason is that neglecting countries preferences is unlikely to be an important omission in practice. It could well be the case that receiving countries have preferences over the ethnic, religious or national origins of immigrants due to common linguistic or cultural characteristics and to shared histories (leading, for example, to the constitution of migration and diaspora networks); to a large extent however, this tends to coincide with the migrants' preferences and to be reflected in their ranking of preferred destinations. Still, receiving countries do have preferences for skilled individuals, or for individuals with specific skills. However, given the types of immigration we are considering in this paper as possible applications for a TIQs system (political refugees, climate change refugees, low-skill immigrants from poor countries), heterogeneity in skills is unlikely to be an issue. On the whole, therefore, it seems reasonable to treat candidate immigrants as essentially identical ex ante from the perspective of receiving countries.

\section{Climate Change, Refugee Protection and Resettle- ment}

The idea of setting up a market for tradable immigration quotas was first advanced in the context of refugees' protection and resettlement. This is not surprising as refugee protection is a classical example of an international public good. In this section we first briefly describe the current refugee protection system and discuss why and how a system of tradable refugees' resettlement quotas could represent a substantial improvement over the current situation. We also discuss the case of climate change refugees, for which a TIQs system along the lines described in Section 2 would seem particularly relevant.

\subsection{Background}

The Geneva Refugee Convention was adopted on 28 July 1951 (UNHCR, 1996). Its Article 1 defines a refugee as "a person who is outside his/her country of nationality or habitual residence; has a well founded fear of persecution because of his/her race, religion, nationality, membership in a particular social group or political opinion; and is unable or unwilling to avail himself/herself of the protection of that country, or to return there for fear of persecution". The 145 countries that signed the 1951 Geneva Convention and/or its extension in the 1967 Protocol committed to admit any person satisfying the above criteria and asking for asylum and to grant that person protection and basic human rights. The number of international refugees as just defined has been relatively stable during the last decade at about 10 million. This is in contrast to the number of Internally Displaced Persons (IDPs), who now represent the bulk of the total "population of concern" to the United Nations High Commissioner for Refugees.

In its preamble, the Geneva Convention recognizes that "the grant of asylum may place unduly heavy burdens on certain countries" and that "a satisfactory solution of a problem

\footnotetext{
${ }^{15}$ See also Sonmez and Unver (2010).
} 
of which the United Nations has recognized the international scope and nature cannot be achieved without international cooperation". Indeed, the "refugee burden" tends to falls disproportionately on countries with low capacity to assume it, usually on countries which are contiguous to the refugees' origin countries and serve as countries of first asylum (UNHCR, 2002). This is generally addressed through relief and emergency aid financed by the international community. However, as time passes, many refugees often find themselves unable to return to their home country due to persistent political, economic or environmental crisis. At the end of 2003, the UNHCR calculated that at least 6.2 million refugees could be considered in "protracted refugee status" (UNHCR, 2004a). ${ }^{16}$ For this type of refugees, resettlement appears as the main durable solution to their condition.

The current system of refugee protection is widely viewed as inefficient and leading to under-provision of refugee protection and asylum at the international level. One of the reasons for this unsatisfactory outcome is that it has long been plagued by a "screening" problem, that is, the difficulty for countries to distinguish between "genuine" refugees seeking asylum and regular economic migrants. The inability to differentiate between these two types of migrants has repeatedly been put forward as justification for tightening the refugee protection policies, resulting in a race to the bottom in refugees' acceptance standards (Barbou des Places and Deffains, 2004, Hatton, 2004, Neumayer, 2004). ${ }^{17}$ This prompted proposals to reform the 1951 Convention, notably during the 1990s when Schuck (1997) and Hathaway and Neve (1997) came up with similar ideas. In the words of Schuck (1997), "the proposal consists of two main elements. First, a group of states would (...) arrange for an existing or newlyestablished international agency to assign to each participating state a refugee protection quota. (...) Second, the participating states would then be permitted to trade their quotas by paying others to fulfill their obligations...", that is, through bilateral exchange.

This section focuses on refugees' resettlement, where a tradable quotas system is probably both most needed and feasible. Indeed, as noted by the UNHCR, "resettlement is an area of activity where multilateral agreements between States have the potential to achieve a significant impact on solving protracted refugee situations and thereby facilitate solutions for a greater number of refugees" (UNHCR, 2004b). We propose to consider refugees in "protracted refugee status" as candidates to international resettlement to at least partially solve the screening problem discussed above: receiving such status takes a long time and would therefore be a very costly detour for obtaining refugee status unduly (see also Bubb, Kremer and Levine, 2011). The potential for improvement over the current situation also comes from the very low number of yearly international resettlements and the tremendous

\footnotetext{
${ }^{16}$ This measure only counted refugees in developing countries who had been in exile for five or more years in refugee camps larger than 25,000. Thus it is likely to be an under-estimation of the total number of refugees that could be considered in "protracted refugee status".

${ }^{17}$ Host countries have complained that the "refugee door" is used by economic migrants as a way to circumvent their restrictive migratory policies. As a result, they tighten their recognition of asylum seekers by imposing even more restrictive policies and preventing access of people that the Geneva Convention would recognize as refugees. This increases the direct burden on the neighboring countries of those who generate refugee crises and lead to situations in which they even close their borders (for example, Tanzania during the 1996 Rwanda refugee crisis).
} 
differences in the contributions of the main stakeholders in this process. In terms of numbers, there are only 100,000 refugees who are resettled on average each year while, as we have seen, there are about 10 million international refugees, including 6 million with protracted status. And in terms of the relocation of these refugees, their distribution across host countries is strikingly unequal (see Table 2).

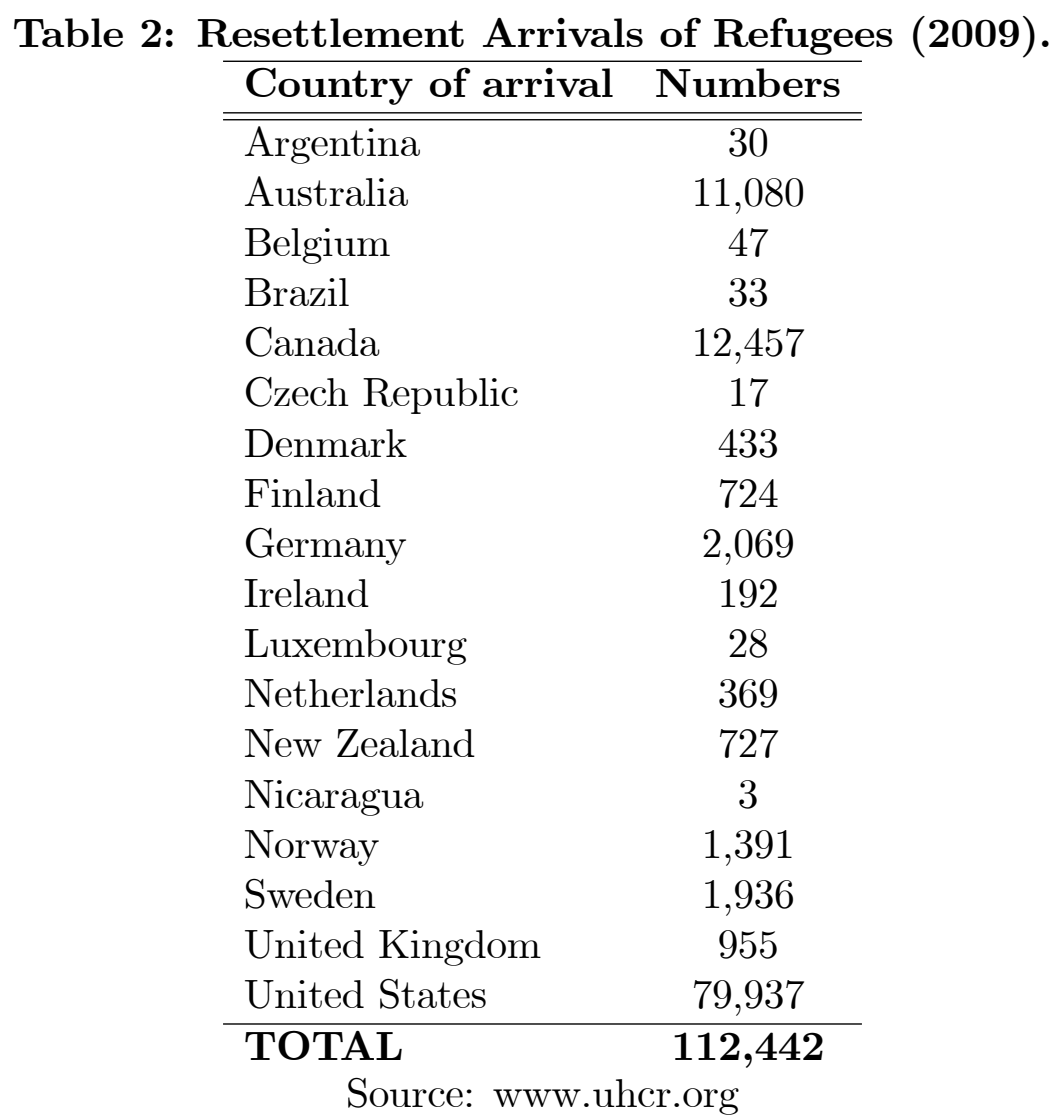

\subsection{Climate Change Refugees}

A system of tradable refugees resettlement quotas would seem even more relevant in the case of climate change refugees for at least three reasons. First, in the case of displacement due to climate change, the need for refugee protection is unlikely to be temporary and requires long-term solutions. Second, it is relatively easy in this case to determine who is entitled to refugee protection. And third, the need for international resettlement is obvious in certain circumstances such as the disappearance of some states, which is likely to happen to a number of small island-states in the Pacific and the Caribbean (Kelman, 2008).

Note however that the term "climate change refugee" is controversial (see Dun and Gemenne, 2008; Stavropoulou, 2008; Barnett and Webber, 2010). For example, the UNHCR limits the use of the term "climate change refugees" to population movements provoked by 
armed conflicts which may have a climate root (e.g., Darfur). ${ }^{18}$ However, in practice, the UNHCR has often played a major role in the aftermath of natural disasters independently of whether they were provoked by civil conflict. This has been the case for the 2004 tsunami in Indonesia and Sri Lanka, the 2005 earthquake and the 2007 floods in Pakistan, the 2006 floods in Somalia or the 2008 cyclone in Myanmar.

Partly due to disputes on terminology and, for the most part, to disagreement on the expected magnitude of climate change, the range of the estimates in terms of numbers of individuals affected by climate change is quite vast. Elverland (2009) calculated that 20 million people were displaced because of climate-related events in 2008 alone. His count included 6.5 million from floods in India, 2 million from a storm in the Philippines and 2 million from a storm in the US. Clearly, these are not the types of displacements (mostly internal and temporary in nature) for which a market for tradable refugee quotas would be an adequate tool. Long-run climate change refugees estimates vary wildly, from twenty million to one billion by 2050. The most widely cited number is Myers' (2005) estimate of 200 million, out of which one million would come from disappearing island states. At least for these one million people, the mechanism proposed here would seem to be entirely appropriate.

\subsection{A market for tradable refugees quotas}

Suppose an international agency (say, the UNHCR) determines that $M$ refugees must be resettled and $N$ countries agree to become resettlement countries and are assigned a quota of refugees based on some agreed upon rule. Assume also that all refugees are already outside of their home country (e.g., in refugee camps) and a market as described above operates among the $N$ possible destination countries. Then the problem is exactly analogous to assigning houses to tenants with existing rights (Abdulkadiroglu and Sonmez, 1999). Since the refugees must always be given the possibility of staying in their country of first asylum (i.e., no individual can be forced into an undesired destination), the right of the refugee to stay in their original location can be considered as their current "house" (see appendix B).

To explain how the proposal could be implemented, we first describe the current resettlement system, which already involves multilateral discussions. Around the month of June of each year, global resettlement policy and quotas are discussed in Geneva during the Annual Tripartite Consultations. This is a series of meetings that includes the countries taking resettlement quotas, the European Commission, non-governmental organizations involved in resettlement activities and the International Organization for Migration. It is around these Annual Tripartite Consultations that the market could be set in motion. Resettlement countries and UNHCR would agree on resettlement quotas for the year ahead in exactly the same way that they do now but this time allowing for the possibility of opening a market to trade these quotas at a future date. The possibility of future trades would allow countries

\footnotetext{
${ }^{18}$ Contrary to the UNHCR, individual countries already recognize extreme events by which they host individuals that do not satisfy the conditions of refugee status. See our discussion of the US temporary protected status in Section 1.2 above.
} 
to establish higher initial resettlement quotas than they would if these were fixed.

One important question regards the initial distribution of quotas among participating countries. The ideal solution would be to set a global resettlement quota and then distribute it through some burden sharing rule. Hatton and Williamson (2004) propose (for the European Union) contributions to the European Refugee Fund in proportion to the countries' GDP and resettlement quotas in proportion to the countries' population. Once the total number $M$ and the initial distribution of quotas $\left\{m_{i 0}\right\}_{i=1}^{N}$ are agreed upon among the $N$ participating resettlement countries, the subset of refugees that will actually be resettled has to be decided. This is critical since the number of refugees that countries are likely to agree upon for resettlement is notably lower than the total number of refugees. UNHCR should be the appropriate agent to select the group of refugees to be resettled, possibly with the help of NGOs. Finally, to make sure that the market is competitive, we follow Casella (1999) in proposing a computerized continuous double auction to organize trades. This departs notably from the original idea of Schuck (1997) and Hathaway and Neve (1997) who proposed bilateral negotiation processes in which the relative strength of the parties was likely to play a more decisive role.

\section{Extending the US Diversity Lottery Visa}

In this section we take inspiration of an existing immigration program, namely, the US diversity lottery visa (or green card lottery) to illustrate the possible workings of a TIQs system.

\subsection{Background: the US Green Card Lottery}

Each year, 50,000 immigration visas are made available through a lottery to people who come from countries with low rates of immigration (less than 50,000 immigrants in the previous five years) to the US. ${ }^{19}$ These visas are termed Diversity Visas and the lottery is known as the Green Card Lottery Program. Individuals from non-excluded countries are eligible if they have at least "a high school education or its equivalent or have, within the past five years, two years of work experience in an occupation requiring at least two years' training or experience". Someone receiving a visa through the Diversity Visa Lottery Program will be authorized to live and work permanently in the United States and will also be allowed to bring the dependents listed on his/her application.

For example, the application process for the 2010 Diversity Lottery program took place between October and November 2008. The only excluded countries were: Brazil, Canada, China (mainland-born, excluding Hong Kong S.A.R., and Taiwan), Colombia, Dominican Republic, Ecuador, El Salvador, Guatemala, Haiti, India, Jamaica, Mexico, Pakistan, Peru,

\footnotetext{
${ }^{19}$ The Nicaraguan and Central American Relief Act (NACARA) passed by Congress in November 1997 stipulated that up to 5,000 of the 55,000 annually-allocated diversity visas should be made available for use under the NACARA program. The reduction of the limit of available visas to 50,000 began in 2000 .
} 
the Philippines, Poland, South Korea, the United Kingdom (except Northern Ireland) and its dependent territories, and Vietnam. There were a total of 13,6 million applications that entered the lottery, out of which the Department of State randomly selected 102,800: a 0.76 percent average probability of winning the lottery, although the actual probabilities differ by country, favoring natives of small-size countries. Nigeria was the country with the highest number of registered applicants (lottery winners) with 6,006, closely followed by Bangladesh $(6,001)$ and Ethiopia $(5,200)$. The final 50,000 visas will come out of these since many applicants will not complete the visa process. Applicants are not provided any type of assistance such as airfare, housing assistance, or subsidies. If selected, they are required to provide evidence that they will not become a public charge in the United States before being issued a visa.

\subsection{An OECD Poverty Reduction Visa?}

It is conceivable to extend the US Diversity Visa Program to other high-income receiving countries and to target potential migrants according to the expected contribution of their immigration to global poverty reduction. Under such an extension, each destination country would be assigned a number of visas (initial quotas) and be allowed to trade them in a centralized market while eligible migration candidates (e.g., residents of poor countries at environmental, political or economic risk) would be asked about their preferences over potential destinations. Implementing such a program would require addressing a number of issues with regards to screening, ${ }^{20}$ market regulation,${ }^{21}$ definition of a fair distribution of initial quotas, and participation of enough destination countries. The last two issues are related in the sense that one can always set the initial allocation of quotas so that there will only be winners. However, as already discussed, taking participation constraints into account requires using information that countries have usually no incentive to reveal (see Appendix A for a formal discussion). In the absence of such readily available information, we can only note that countries do sign international agreements even if they lose on issues such as the environment, refugee protection, or ban of whales hunting when there is a clear sense that an important international public good is provided (leading to strong international pressure on individual countries to sign) and there is a perception that contributions are shared fairly. We believe these conditions apply to global poverty reduction, the first of the Millennium Development Goals, but have otherwise little to say on this question beyond the general principles recalled above and emphasized in the international law literature. ${ }^{22}$

We present a simple numerical simulation of the way an OECD Poverty Reduction Visa could be implemented. To determine initial quotas, we assume participation of all the highincome countries, set the total number of visas that the US would award at the current size

\footnotetext{
${ }^{20}$ In the case of the US Diversity Visa, the US Department of State screens applicants both for economic and security reasons; in an OECD-extended framework, either a common screening procedure or a procedure where each country has veto right on who to let in would have to be agreed upon.

${ }^{21}$ Here we again follow Casella (1999) in proposing a computerized continuous double auction to organize trades.

${ }^{22}$ See for example Dai (2007), among many others.
} 
of the US Diversity Program (50,000) and assign quotas to the other countries so that they are proportional to GDP. Since the US GDP represents 36 percent of the high-income OECD countries in 2008, this implies setting the total number of visas to 140,140 (see Table 3 for the distribution).

One of the main functions of the proposed mechanism is to help countries discover the real shape of their country-specific cost functions: $c_{i}\left(m_{i}\right)$ in our model, for which we have to choose a specification to perform the simulation. De la Croix and Docquier (2010), for example, choose the function $\frac{\gamma_{i}}{2}\left(\frac{m_{i}}{n_{i}}\right)^{2},{ }^{23}$ where $n_{i}$ is the number of natives in country $i$ and $\gamma_{i}$ is a country-specific parameter that can be interpreted as the degree of aversion to immigration. They calibrate it to match the observed distribution of migration stocks across rich countries. In our simulation, we arbitrarily choose the following specification: ${ }^{24}$

$$
c_{i}\left(m_{i}\right)=\frac{\gamma_{i}}{2} \frac{m_{i}^{2}}{p o p_{i}}
$$

Defining рор $_{i}$ as the total population of country $i$, this allows us to write marginal costs as a linear function of the new migration share:

$$
c_{i}^{\prime}\left(m_{i}\right)=\gamma_{i} \frac{m_{i}}{\text { pop }_{i}}
$$

This simple marginal cost function implies that countries do not want to receive any more migrants than they currently have. In other words, we here interpret $m_{i}$ as denoting the new immigrants only while previously accepted immigrants are considered part of the population.

We present two different simulations. In the first one, we assign to $\gamma_{i}$ the following values from the 2003 ISSP National Identity Module (Facchini and Mayda, 2008): "share of respondents who believe immigration should be reduced a lot." We interpret this as a proxy for anti-immigration attitudes. Since the numbers we are going to calculate are

${ }^{23}$ In De la Croix and Docquier (2010), countries maximize the following national utility function:

$$
U_{i}=u\left(C_{i}\right)+\beta u\left(C_{o}\right)-\frac{\gamma_{i}}{2}\left(\frac{m_{i}}{n_{i}}\right)^{2}
$$

where $C_{i}$ is the consumption level of country $i$ inhabitants, $C_{o}$ is the consumption level of poor country individuals (positively affected by migration and $\beta$ is a parameter that denotes altruism towards poor country individuals when positive. Positive values of $\beta$ are one possible way of formalizing the externality.

${ }^{24}$ In fact, the exact translation between De la Croix and Docquier's (2010) model and ours would mean that:

$$
g_{i}\left(M_{-i}\right)-c_{i}\left(m_{i}\right)=u\left(C_{i}\left(m_{i}\right)\right)+\beta u\left(C_{o}\left(M_{-i}\right)\right)-\frac{\gamma_{i}}{2}\left(\frac{m_{i}}{n_{i}}\right)^{2}
$$

Both functional forms are equally arbitrary but they serve the purpose of illustrating the mechanism.

Note that we do not "believe" in a particular specification, the very purpose of the proposed mechanism being precisely to reveal the "true" immigration cost function, and choose the above cost functions for illustrative purposes only. 
just illustrative, we are not concerned about what the right measure of anti-immigration sentiment should be. We take the first of the five answers so that it provides us with sufficient variability to generate gains from trading.

The results can be observed in Table 3, column 3 . The countries with relatively low GDP and low anti-immigration sentiment would become quota buyers and receive a monetary compensation in return: Spain, Canada, Japan, Portugal and Australia would all host at least one thousand immigrants in excess of their initial quota. On the other side of the market, Germany, the UK, France, the USA, the Netherlands and Norway would be willing to sell more than one thousand of their assigned quotas, paying to avoid hosting more immigrants. All in all, 16 percent of the total number of quotas would be traded, generating an efficiency gain of 17 percent of the total cost compared to the initial quota allocation.

In our second parameterization, we identify $\gamma_{i}$ with the inverse of the 1990-2000 net migration flows of non-tertiary educated individuals from low-income countries received by country $i$ ( taken from Docquier and Marfouk (2006) - see Table 1) to population in country $i$. The intuition behind this measure is that the acceptance of immigrants during the 1990-2000 is a de facto measure of the degree of anti-immigration sentiment. The results of a market for TIQs assuming our second measure of anti-immigration sentiment can also be read from Table 3 . This time, the main quota buyers would be the USA, the UK, Australia and Canada with more than one thousand extra immigrants received in exchange for widely varying cost reductions with respect to their original quotas (between 141 percent for Australia and 19 percent for the USA). The main sellers, those who pay for accepting less immigrants than they are initially assigned, would be Japan, Germany, Italy and Spain in this order, all with more than three thousand quotas sold. In summary, the cost reduction would be 57 percent and the traded quotas would amount to 13 percent of the total.

Obviously, the two simulations yield very different results, reinforcing our view that immigration cost functions can hardly be calibrated using real world data and can only be exposed through a revelation mechanism such as a TIQs system. 
Table 3: Simulations of an OECD Poverty Reduction Visa with a market for TIQs

\begin{tabular}{|c|c|c|c|c|c|c|c|}
\hline Countries & $\begin{array}{l}\text { Initial } \\
\text { quotas }\end{array}$ & $\begin{array}{c}\text { Aversion 1: } \\
\text { ISSP } \\
2003\end{array}$ & $\begin{array}{c}\text { Market } \\
\text { Quota } \\
1\end{array}$ & $\begin{array}{c}\text { Cost } \\
\text { Reduc. } 1 \\
\text { v. initial } \\
\text { quota }\end{array}$ & $\begin{array}{c}\text { Aversion 2: } \\
\text { inv. flows } \\
90-00 \text { over } \\
\text { total pop. }\end{array}$ & $\begin{array}{c}\text { Market } \\
\text { Quota } \\
2\end{array}$ & $\begin{array}{c}\text { Cost } \\
\text { Reduc. } 2 \\
\text { v. initial } \\
\text { quota }\end{array}$ \\
\hline Australia & 3,602 & 16.8 & 4,681 & $9 \%$ & 393 & 7,882 & $141 \%$ \\
\hline Austria & 1,467 & 32.7 & 934 & $13 \%$ & 3318 & 363 & $57 \%$ \\
\hline Belgium & 1,789 & 26.0 & 1,510 & $2 \%$ & 4714 & 328 & $67 \%$ \\
\hline Canada & 5,326 & 10.2 & 11,965 & $155 \%$ & 600 & 8,024 & $26 \%$ \\
\hline Denmark & 1,211 & 25.9 & 779 & $13 \%$ & 477 & 1,667 & $14 \%$ \\
\hline Finland & 967 & 15.8 & 1,231 & $7 \%$ & 1198 & 641 & $11 \%$ \\
\hline France & 10,134 & 35.4 & 6,457 & $13 \%$ & 1096 & 8,217 & $4 \%$ \\
\hline Germany & 12,948 & 44.3 & 6,799 & $23 \%$ & 2598 & 4,569 & $42 \%$ \\
\hline Greece & 1,263 & 26.0 & 1,585 & $7 \%$ & 84620 & 19 & $97 \%$ \\
\hline Iceland & 59 & 26.0 & 45 & $6 \%$ & 420 & 109 & $72 \%$ \\
\hline Ireland & 949 & 27.7 & 587 & $15 \%$ & 3221 & 199 & $63 \%$ \\
\hline Italy & 8,171 & 26.0 & 8,439 & $0 \%$ & 2180 & 3,969 & $26 \%$ \\
\hline Japan & 17,423 & 20.2 & 23,242 & $11 \%$ & 4983 & 3,705 & $62 \%$ \\
\hline Luxembourg & 191 & 26.0 & 69 & $41 \%$ & 1861 & 38 & $64 \%$ \\
\hline Netherlands & 3,090 & 37.8 & 1,594 & $23 \%$ & 1010 & 2,354 & $6 \%$ \\
\hline N. Zealand & 461 & 26.8 & 584 & $7 \%$ & 955 & 646 & $16 \%$ \\
\hline Norway & 1,603 & 36.4 & 481 & $49 \%$ & 522 & 1,321 & $3 \%$ \\
\hline Portugal & 864 & 19.1 & 2,041 & $186 \%$ & 1077 & 1,425 & $42 \%$ \\
\hline Spain & 5,691 & 13.2 & 12,657 & $150 \%$ & 2762 & 2,384 & $34 \%$ \\
\hline Sweden & 1,699 & 25.6 & 1,323 & $5 \%$ & 540 & 2,466 & $20 \%$ \\
\hline Switzerland & 1,745 & 16.9 & 1,659 & $0 \%$ & 1143 & 967 & $20 \%$ \\
\hline UK & 9,487 & 50.9 & 4,427 & $28 \%$ & 519 & 17,119 & $65 \%$ \\
\hline USA & 50,000 & 23.7 & 47,050 & $0 \%$ & 613 & 71,725 & $19 \%$ \\
\hline Total & $\overline{140,140}$ & 26.6 & 10140,140 & $17 \%$ & 22280.0 & $\overline{14140,140}$ & $57 \%$ \\
\hline $\begin{array}{l}\text { Quotas } \\
\text { traded }\end{array}$ & & & $16 \%$ & & & $13 \%$ & \\
\hline
\end{tabular}




\section{Conclusion}

Providing international migration opportunities (visas) to low-skill immigrants from poor countries contributes to global poverty alleviation, an international public good. The current management of international migration, where each country sets its immigration policy independently of the others, fails to internalize such externality and therefore results in a global underprovision of immigration visas. We contend that a market for tradable immigration quotas (TIQs) would go part of the way towards addressing the inefficiencies of the current system and allow for allocating a larger overall number of international migrants at a lower total cost. Countries with high marginal costs for receiving additional immigrants would compensate countries with low marginal costs to host them. In addition, the proposed system would take into account migrants' preferences by using a matching mechanism to assign migrants to their preferred destinations. The main advantage of a TIQs system over alternative proposals to increase international migration flows rests on its ability to elicit information on the true country-specific costs of hosting additional migrants; once these are revealed, a TIQs system also offers a framework to realize the welfare gains arising from the fact that certain countries have a (dynamic?) comparative advantage in hospitality.

Specifically, we considered two situations in which a system of tradable immigration quotas would seem a natural extension of existing policies and, therefore, quite feasible: a market for the resettlement of international refugees (especially in the case of long-term displacements such as climate change refugees from small disappearing island-states); and the creation of an OECD poverty reduction visa on the model of the US Diversity Visa program but extended to other high-income destinations and targeting potential migrant populations according to the contribution of their immigration to global poverty alleviation. Both applications allow for considerable experimentation and learning and are seen as possible precursors to a larger implementation of a TIQs system. 


\section{References}

[1] Abdulkadiroglu, A. and T. Sonmez (1999): House Allocation with Existing Tenants, Journal of Economic Theory, 88: 233-260

[2] Barbou Des Places, S. and B. Deffains (2004): Cooperation in the shadow of regulatory competition: the case of asylum legislation in Europe, International Review of Law and Economics 23: 345-364

[3] Barnett, J. and Webber, M. (2010): Accommodating Migration to Promote Adaptation to Climate Change, World Bank Policy Research Working Paper 5270. Background Paper to the 2010 World Development Report.

[4] Baumol, W. J. and W. E. Oates (1995): The theory of environmental policy. Second Edition. Cambridge University Press.

[5] Bubb, R., M. Kremer and D. I. Levine (2011): The Economics of International Refugee Law, Journal of Legal Studies, forthcoming.

[6] Casella, A. (1999): Tradable Deficit Permits. Efficient Implementation of the Stability Pact, Economic Policy 29: 323-347

[7] Chen, Y. and T. Sonmez (2002): Improving Efficiency of On-Campus Housing: An Experimental Study, American Economic Review, 92 (5): 1669-1686

[8] Clemens, M. and L. Pritchett (2008): Income per natural, Population and Development Review, 34 (3): 395-434

[9] Clemens, M., C. Montenegro and L. Pritchett (2008): The place premium: wage differences for identical workers across the US border, CGD Working Paper No 148, Washington DC: Center for Global Development.

[10] Coase, R. (1960): The Problem of Social Cost, Journal of Law and Economics, 3: 1-44

[11] Dai, X. (2007): International Institutions and National Policies, Cambridge, Ma: Cambridge University Press.

[12] De la Croix, D. and F. Docquier (2010): An Incentive Mechanism to Break the Low-skill Immigration Deadlock, CREAM Discussion Paper No 08/10, May.

[13] De la Croix, D. and A. Gosseries (2007): Procreation, Migration, and Tradable Quotas, in Population Aging, Intergenerational Transfers and the Macroeconomy, edited by R. Clark, A.Mason and N. Ogawa. Edward Elgar Publishing: 227-249.

[14] Docquier, F. and A. Marfouk (2006): International migration by educational attainment (1990-2000), in International Migration, Remittances and Development, edited by C. Ozden and M. Schiff. Palgrave Macmillan: New York. 
[15] Dun, O. and Gemenne, F. (2008): Defining ‘environmental migration', Forced Migration Review, 31, 10-11.

[16] Easterly, W. (2001): The elusive quest for growth, Princeton: Princeton University Press.

[17] Elverland, S. (2009): 20 million Climate Displaced in 2008, Norwegian Refugee Council, available at: http://www.nrc.no/?did=9407544

[18] Facchini, G. and A. M. Mayda (2008): From individual attitudes towards migrants to migration policy outcomes: Theory and evidence, Economic Policy 23: 651-713

[19] Fernández-Huertas Moraga, J. (2011): New evidence on emigrant selection, The Review of Economics and Statistics 93 (1): 72-96.

[20] Gale, D. and L. Shapley (1962): College Admissions and the Stability of Marriage, American Mathematical Monthly 69, 9-15.

[21] Hanson, G.H. (2009): The economic consequences of the international migration of labor, Annual Review of Economics, 1: 179-208.

[22] Hanson, G. H., K. Scheve and M. J. Slaughter (2007): Public Finance And Individual Preferences Over Globalization Strategies, Economics and Politics 19 (1): 1-33

[23] Hathaway, J. C. and R. A. Neve (1997): Making International Refugee Law Relevant Again: A Proposal for Collectivized and Solution-Oriented Protection, Harvard Human Rights Journal, 10: 115-211

[24] Hatton, T. J. (2004): Seeking asylum in Europe, Economic Policy, 19 (38): 5-62

[25] Hatton, T. J. and J. G. Williamson (2004): Refugees, Asylum Seekers and Policy in Europe, NBER Working Paper 10680

[26] Kelman, I. (2008): Island evacuation, Forced Migration Review, 31, 20-21.

[27] Mayda, A. M. (2008): Why are people more pro-trade than pro-migration?, Economics Letters, 101 (3): 160-163

[28] McKenzie, D., J. Gibson and S. Stillman (2010): How important is selection? Experimental vs. Non-Experimental Measures of the Income Gains from Migration, Journal of the European Economic Association, 8, 4: 913-945

[29] McKenzie, D. and H. Rapoport (2007): Network effects and the dynamics of migration and inequality: theory and evidence from Mexico, Journal of Development Economics, 84, 1: 1-24

[30] McKenzie, D. and H. Rapoport (2010): Self-selection patterns in US-Mexico migration: the role of migration networks, The Review of Economics and Statistics 92 (4): 811-821. 
[31] Mishra, P. (2007): Emigration and wages in source countries: evidence from Mexico, Journal of Development Economics, 82, 1: 180-99

[32] Myers, N. (2005): Environmental Refugees: An emergent security issue, 13th Economic Forum, Prague

[33] Neumayer, E. (2004): Asylum Destination Choice: What Makes some European Countries more Attractive than Others?, European Union Politics, 5 (2): 155-180

[34] O'Rourke, K. H. and Sinnott, R. (2006): The determinants of individual attitudes towards immigration, European Journal of Political Economy 22 (4): 838-861

[35] Pritchett, L. (2006): Let their people come. Breaking the gridlock on global labor mobility, Washington, DC: Center for Global Development.

[36] Pritchett, L. (2010): The cliff at the border; in Ravi Kanbur and Michael Spence, eds.: Equity and Growth in a Globalizing World, Washington DC, World Bank, Commission on Growth and Development, forthcoming.

[37] Rapoport, H. and F. Docquier (2006): The economics of migrants' remittances, in S.-C. Kolm and J. Mercier Ythier, eds.: Handbook of the Economics of Giving, Altruism and Reciprocity, Amsterdam: North Holland, Chapter 17.

[38] Rodrik, D. (2007): One economics, many recipes: globalization, institutions and economic growth, Princeton: Princeton University Press.

[39] Roth, A. E. (1985): The College Admissions Problem is not Equivalent to the Marriage Problem, Journal of Economic Theory 36, 277-288

[40] Roth, A. E. (2002): The Economist as an Engineer: Game Theory, Experimental Economics and Computation as Tools of Design Economics, Econometrica, 70 (4): 13411378

[41] Schuck, P. H. (1997): Refugee Burden-Sharing: A Modest Proposal, Yale Journal of International Law, 22: 243-297

[42] Shen, I.-L., F. Docquier and H. Rapoport (2010): Remittances and inequality: a dynamic migration model, Journal of Economic Inequality, 8, 2: 197-220

[43] Sonmez, T. and M. U. Unver (2010): Matching, Allocation and Exchange of Discrete Resources, in J. Benhabib, A. Bisin and M. Jackson, eds.: Handbook of Social Economics, Amsterdam: North Holland.

[44] Stavropoulou, M. (2008): Drowning in definitions?, Forced Migration Review, 31, 11-12.

[45] UNHCR (1996): Convention and Protocol Relating to the Status of Refugees. United Nations High Commissioner for Refugees. Geneva. March. 
[46] UNHCR (2002): Selected Indicators Measuring Capacity and Contributions of Host Countries. Population Data Unit. Population and Geographical Data Section. United Nations High Commissioner for Refugees. Geneva. April.

[47] UNHCR (2004a): Protracted Refugee Situations. Executive Committee of the High Commissioner's Programme. Standing Committee 30th Meeting. 10 June.

[48] UNHCR (2004b): Progress Report on Resettlement. Executive Committee of the High Commissioner's Programme. Standing Committee 30th Meeting. 7 June.

[49] UNHCR (2009): Forced Displacement in the Context of Climate Change: Challenges for States Under International Law, Paper submitted by the Office of the United Nations High Commissioner for Refugees in cooperation with the Norwegian Refugee Council, the Representative of the Secretary General on the Human Rights of Internally Displaced Persons and the United Nations University to the 6th session of the Ad Hoc Working Group on Long-Term Cooperative Action under the Convention (AWG-LCA 6) from 1 until 12 June in Bonn.

[50] Walmsley, T.L., A.L. Winters and S.A. Ahmed (2009): The Impact of the Movement of Labour: Results from a Model of Bilateral Migration Flows, Mimeo., University of Sussex.

[51] Weitzman, M. L. (1974): Prices vs. Quantities, The Review of Economic Studies, 41 (4): 477-491

[52] World Bank (2006): Global Economic Prospects. World Bank, Washington D.C.

[53] World Bank (2008): Migration and Remittances Factbook 2008. World Bank, Washington D.C. 


\section{Appendix}

\subsection{Appendix A: Taking participation constraints into account.}

The general formulation of the problem in which the countries participation constraints are satisfied is:

$$
\begin{aligned}
\max _{\left\{m_{i 0}\right\}_{i=1}^{N}} \sum_{i=1}^{N}\left[g_{i}\left(M_{-i}^{M}\right)-c_{i}\left(m_{i}^{M}\right)\right] & \\
\text { s.t. } \sum_{i=1}^{N} m_{i 0} & =M \\
g_{i}\left(M_{-i}^{M}\right)-c_{i}\left(m_{i}^{M}\right)+p\left(m_{i}^{M}-m_{i 0}\right) & \geq g_{i}\left(M_{-i}^{N C}\right)-c_{i}\left(m_{i}^{N C}\right) \quad \forall i=1 \ldots N \\
m_{i}^{M} & =\arg \min \left\{c_{i}\left(m_{i}\right)-p\left(m_{i}-m_{i 0}\right)\right\} \quad \forall i=1 \ldots N
\end{aligned}
$$

The first order conditions are:

$$
\begin{aligned}
\mu-p \pi_{i} & =0 \quad \forall i=1 \ldots N \\
\sum_{i=1}^{N} m_{i 0}-M & =0 \\
\pi_{i}\left[g_{i}\left(M_{-i}^{M}\right)-c_{i}\left(m_{i}^{M}\right)+p\left(m_{i}^{M}-m_{i 0}\right)-g_{i}\left(M_{-i}^{N C}\right)+c_{i}\left(m_{i}^{N C}\right)\right] & =0 \quad \forall i=1 \ldots N \\
\pi_{i} & \geq 0
\end{aligned}
$$

where $\mu$ is associated to $\sum_{i=1}^{N} m_{i 0}=M$ and $\pi_{i}$ is associated to $g_{i}\left(M_{-i}^{M}\right)-c_{i}\left(m_{i}^{M}\right)+$ $p\left(m_{i}^{M}-m_{i 0}\right) \geq g_{i}\left(M_{-i}^{N C}\right)-c_{i}\left(m_{i}^{N C}\right)$. We are using the fact that $\frac{\partial m_{j}^{M}}{\partial m_{i 0}}=0=\frac{\partial p}{\partial m_{i 0}} \forall i, j$ since the solution to the market problem does not depend on the initial allocation of quotas.

From the first set of conditions, we have:

$$
\pi_{i}=\frac{\mu}{p}>0 \quad \forall i=1 \ldots N
$$

This leaves us with a rule to allocate initial quotas satisfying:

$$
g_{i}\left(M_{-i}^{M}\right)-c_{i}\left(m_{i}^{M}\right)+p\left(m_{i}^{M}-m_{i 0}\right)-g_{i}\left(M_{-i}^{N C}\right)+c_{i}\left(m_{i}^{N C}\right)=0 \quad \forall i=1 \ldots N
$$

which implies:

$$
m_{i 0}=m_{i}^{M}+\frac{g_{i}\left(M_{-i}^{M}\right)-g_{i}\left(M_{-i}^{N C}\right)}{p}-\frac{c_{i}\left(m_{i}^{M}\right)-c_{i}\left(m_{i}^{N C}\right)}{p} \quad \forall i=1 \ldots N
$$


The countries benefitting the most from the externality (higher $g_{i}\left(M_{-i}^{M}\right)-g_{i}\left(M_{-i}^{N C}\right)$ ) should get higher initial quotas whereas those who deviate most from their individually optimal migration level because of the market (higher $c_{i}\left(m_{i}^{M}\right)-c_{i}\left(m_{i}^{N C}\right)$ ) should get lower initial quotas.

It must be the case that:

$$
\sum_{i=1}^{N}\left[g_{i}\left(M_{-i}^{M}\right)-g_{i}\left(M_{-i}^{N C}\right)\right]=\sum_{i=1}^{N}\left[c_{i}\left(m_{i}^{M}\right)-c_{i}\left(m_{i}^{N C}\right)\right]
$$

The overall gain from the market must equate the overall cost of the market for a maximum utility level to be obtained.

\subsection{Appendix B: Application of the top trading cycles mechanism to refugees resettlement}

The application of the top trading cycles mechanism to the refugee problem would work as follows:

1. Each refugee ranks all potential destination countries, specifying those to which she would not want to be resettled at all.

2. An ordering of refugees is randomly chosen from a given distribution of orderings.

3. For any given ranking of countries done by the refugees and ordering of refugees, the outcome is obtained using the following algorithm:

(a) Assign the first refugee (from the ordering obtained in step 2) her top choice, the second refugee her top choice among the remaining visas, and so on, until someone requests a visa for which the quota (resulting from the market) is filled. It is as if the first refugee with a visa in that quota is requested to exchange her visa $^{2526}$.

(b) If at that point, the refugee whose visa is requested has already chosen before, then go to the second refugee in that quota. If this one has also chosen, go to the third

\footnotetext{
${ }^{25}$ How can this situation take place? For example, suppose that there are 10 refugees to be resettled. 5 of them stay in a refugee camp in country A and 5 in another refugee camp in country B. Suppose the market assigns 3 refugees to A, 5 to $\mathrm{B}$ and 2 to a third country $\mathrm{C}$. This information is summarized in:

Countries $\quad A \quad B \quad C$

Initial situation $\quad 5 \quad 5 \quad 0$

Market $\quad 3 \quad 5 \quad 2$

Suppose the first refugee to choose is staying in country A and decides to request a visa for country B. It is as if she has requested one of the visas that one of the refugees (the second in the ordering in step 2) is already holding.

${ }^{26}$ Notice that when the country of first asylum is unique, the top trading cycles mechanism is equivalent to the random serial dictatorship.
} 
and so on. If the quota is filled with refugees who have already chosen before, then do not disturb the procedure (there is no room for Pareto improvement). Otherwise, modify the remainder of the ordering by inserting the refugee who did not choose yet to the top of the line and go on with the procedure ${ }^{27}$.

(c) Similarly, insert any refugee who is not already served at the top of the line once her visa (to stay in her first asylum country) is requested.

(d) If at any point a loop forms, it is formed exclusively by refugees with a visa each of them requesting the visa of the refugee who is next in the loop (a loop is an ordered list of refugees $\left(j_{1}, j_{2}, \ldots, j_{k}\right)$ where refugee $j_{1}$ requests the visa of refugee $j_{2}$, refugee $j_{2}$ requests the visa of refugee $j_{3} \ldots$, refugee $j_{k}$ requests the visa of refugee $j_{1}$ ). In such cases, remove all refugees in the loop by assigning them the visas they request and continue the procedure.

A key ingredient of this mechanism is that a refugee whose visa is requested is upgraded to the first place at the remaining of the line before her visa is allocated. As a result, the top trading cycles mechanism is individually rational, as it assures every refugee a visa that is at least as good as the possibility of staying in her first-asylum country. It is also incentive compatible (no refugee has an incentive to misrepresent her preferences whatever the strategies others use) and Pareto efficient.

So far, this is a direct application of Abdulkadiroglu and Sonmez (1999) following directly the exposition in Chen and Sonmez (2002) and substituting word by word house for visa and refugee for tenant. The relevant point for the case of refugees studied here is the possibility that the final allocation determined by the market might not be achieved. This can be seen in the following example:

Example 1 Suppose the international community decides 3 refugees must be resettled. There are three countries willing to host them: $A, B$ and $C$. The country of first asylum is country $A$ for the first two refugees and country $C$ for the last one. Suppose that the original distribution of quotas is the following:

$$
m_{A}^{0}=1 ; \quad m_{B}^{0}=1 ; \quad m_{C}^{0}=1
$$

Now, the market opens, trade takes place and the following distribution of quotas is attained:

$$
m_{A}^{M}=0 ; \quad m_{B}^{M}=2 ; \quad m_{C}^{M}=1
$$

There are 216 different refugee preference profiles that will generate different outcomes once the matching mechanism is applied. As an illustration, six of these preference profiles

\footnotetext{
${ }^{27}$ Following the previous example, the first refugee in country B is now at the top of the list and can choose before the previous one does so that there is a possibility that her position is freed if she chooses country A or C.
} 
will be considered by fixing the preferences of the third refugee and assuming that the first two refugees have identical preferences:

$\begin{array}{cccccc}1 & \text { Preferences } & \begin{array}{c}\text { First } \\ \text { Asylum }\end{array} & \begin{array}{c}\text { Final } \\ \text { Resettlement }\end{array} & \\ \text { fugee 1 } & A \succ B \succ C & A & A & m_{A}^{*}=2>m_{A}^{M} \\ \text { fugee 2 } & A \succ B \succ C & A & A & m_{B}^{*}=1<m_{B}^{M} \\ \text { fugee 3 } & A \succ B \succ C & C & B & m_{C}^{*}=0<m_{C}^{M}\end{array}$

The ordering of the refugees is taken randomly, as suggested in the step 1 of the top trading cycles mechanism. In this first example, refugees 1 and 2 prefer to stay in their first asylum country $A$ whereas 3 chooses to move to country $B$, where there are two visas available.

$\begin{array}{cccccc}\text { 2 } & \text { Preferences } & \begin{array}{c}\text { First } \\ \text { Asylum }\end{array} & \begin{array}{c}\text { Final } \\ \text { Resettlement }\end{array} & \\ & m_{A}^{*}=2>m_{A}^{M} \\ \text { fugee 1 } & A \succ C \succ B & A & A & \Longrightarrow & m_{B}^{*}=1<m_{B}^{M} \\ \text { fugee 2 } & A \succ C \succ B & A & A & & m_{C}^{*}=0<m_{C}^{M}\end{array}$

This second case works the same way as the first one.

$\begin{array}{clcccc}\text { 3 } & \text { Preferences } & \begin{array}{c}\text { First } \\ \text { Asylum }\end{array} & \begin{array}{c}\text { Final } \\ \text { Resettlement }\end{array} & \\ \text { Refugee 1 } & B \succ A \succ C & A & B & m_{A}^{*}=0=m_{A}^{M} \\ \text { Refugee 2 } & B \succ A \succ C & A & B & m_{B}^{*}=2=m_{B}^{M} \\ \text { Refugee 3 } & A \succ B \succ C & C & C & m_{C}^{*}=1=m_{C}^{M}\end{array}$

In this third preference profile, refugees 1 and 2 take the two visas that country $B$ offers so that refugee 3 has to stay in country $C$. The market allocation is maintained under the matching mechanism in this case.

First Final

$4 \quad$ Preferences

$\begin{array}{llcccc} & \text { Asylum } & \text { Resettlement } & & m_{A}^{*}=0=m_{A}^{M} \\ \text { Refugee 1 } & B \succ C \succ A & A & B & \Longrightarrow & m_{B}^{*}=2=m_{B}^{M} \\ \text { Refugee 2 } & B \succ C \succ A & A & B & & m_{C}^{*}=1=m_{C}^{M} \\ \text { Refugee 3 } & A \succ B \succ C & C & C & \end{array}$

The fourth preference profile is also compatible with the market allocation.

$\begin{array}{cccccc}5 & \text { Preferences } & \text { First } & \text { Final } & \\ & \text { Asylum } & \text { Resettlement } & & m_{A}^{*}=1>m_{A}^{M} \\ \text { fugee 1 } & C \succ A \succ B & A & C & \Longrightarrow & m_{B}^{*}=1<m_{B}^{M} \\ \text { fugee 2 } & C \succ A \succ B & A & A & & m_{C}^{*}=1=m_{C}^{M} \\ \text { fugee 3 } & A \succ B \succ C & C & B & \end{array}$

In this case, refugee 1 demands the only visa available for country $C$. Since this visa belongs to refugee 3, refugee 3 gets to choose first. Refugee 3 chooses one of the two visas available for country $B$ since there is no visa available for country $A$, her most preferred one. Then, refugee 1 can choose and take the visa for country $C$ that has become available. Finally, refugee 2 can choose to go to country $B$, where there is still one visa available, or to remain in country $A$, which is her selected option. 


$\begin{array}{cccccc}6 & \text { Preferences } & \text { First } & \text { Final } & \\ \text { Asylum } & \text { Resettlement } & & m_{A}^{*}=1>m_{A}^{M} \\ \text { Refugee 1 } & C \succ B \succ A & A & C & \Longrightarrow & m_{B}^{*}=1<m_{B}^{M} \\ \text { Refugee 2 } & C \succ B \succ A & A & A & & m_{C}^{*}=1=m_{C}^{M} \\ \text { Refugee 3 } & A \succ B \succ C & C & B & \end{array}$

The reasoning in this case is the same as in the previous one so that the market allocation is not reached.

A more extreme example can be considered in which the matching mechanism distorts the allocation initially established by the market. Suppose that the preferences of refugees are such that, even though they would be willing to go to other countries (suppose $m_{i}^{a}=M$ for all $i=1 \ldots N$ ), they prefer the neighboring country of first asylum (country $n$ ). As long as $M>m_{n}^{M}$, it is clear that the cost minimizing allocation suggested by the market won't be realized. As a result, we have to differentiate the market allocation $\left\{m_{i}^{M}\right\}_{i=1}^{N}$ from the realized allocation once the matching mechanism comes into place: $\left\{m_{i}^{*}\right\}_{i=1}^{N}$. Both allocations will be different whenever $m_{n}^{*}>m_{n}^{M}$, which implies that $m_{h}^{*}<m_{h}^{M}$ for some $h \neq n$. Notice that it cannot be the case that the realized allocation implies taking more refugees than those allocated for the market for any country who is not the first asylum country, that is $\nexists i \neq n \quad$ s.t. $\quad m_{i}^{*}>m_{i}^{M}$. This is the main difference with the general immigration case presented in the main text. Since the original refugee camps are included as potential destinations, we allow for the possibility that the allocation of the matching mechanism ends up assigning a larger number of refugees to a particular country (where a refugee camp is located) than that resulting from the market.

In such cases, it is clear that costs are not minimized for countries $n$ and $h$. However, the relevant comparison is not with the market unfeasible (in that case) solution but with an alternative system or lack of system like the one that is prevalent nowadays by which most of the refugees stay in the first-asylum country in very poor conditions without this country being compensated (at least it would be compensated under the market system by the refugees in excess of its market quota times the market price). Also, it can be said that country $h$ is punished with a higher cost for not being a desirable enough destination for refugees. In this sense, the initial distribution of quotas $\left(\left\{m_{i 0}\right\}_{i=1}^{N}\right)$ is crucial to avoid that low capacity countries are forced to pay an excessive price for participating in the system.

If the matching mechanism is taken into account, the problem that a central authority would need to solve in order to minimize the total costs of resettling $M$ refugees in $N$ different countries is the following:

$$
\begin{aligned}
& \min _{\left\{m_{i}\right\}_{i=1}^{N}} \sum_{i=1}^{N} c_{i}\left(m_{i}^{*}\right) \\
& \text { s.t. } \quad \sum_{i=1}^{N} m_{i}^{*} \geq M \\
& m_{i}^{*}=F_{i}\left(m_{1}, m_{2}, \ldots, m_{N}\right) \quad \forall i=1 \ldots N
\end{aligned}
$$


Notice the difference with the general market for immigration quotas. Since the original refugee camps are included in the mechanism, the first constraint is $\sum_{i=1}^{N} m_{i}^{*} \geq M$ rather than $\sum_{i=1}^{N} m_{i} \geq M$.

The solution to the total minimum cost problem above can be obtained from the following first order conditions:

$$
\sum_{j=1}^{N} \frac{\partial F_{j}}{\partial m_{i}}\left(c_{j}^{\prime}\left(m_{j}^{*}\right)-\lambda\right)=0 \quad \forall i=1 \ldots N
$$

where $\lambda$, as before, is the multiplier associated with the first constraint.

In the case of the market, the problem a representative country $i$ would face is exactly the same as in the previous section:

$$
\begin{aligned}
& \quad \min _{m_{i}} c_{i}\left(m_{i}^{*}\right)-p\left(m_{i}^{*}-m_{i 0}\right) \\
& \text { s.t. } \quad m_{i}^{*}=F_{i}\left(m_{1}, m_{2}, \ldots, m_{N}\right)
\end{aligned}
$$

The first order condition, as before, is:

$$
\frac{\partial F_{i}}{\partial m_{i}}\left(c_{i}^{\prime}\left(m_{i}^{*}\right)-p\right)=0
$$

It is clear that at least one of the competitive solutions $\left(c_{i}^{\prime}\left(m_{i}^{*}\right)=p\right)$ would replicate the total minimum cost solution. 